\title{
Experimental comparison of dyspnea and pain
}

\author{
Andreas Von Leupoldt ANd Bernhard DAHME \\ University of Hamburg, Hamburg, Germany
}

\begin{abstract}
Dyspnea and pain are similarly unpleasant, alarming physical sensations, but studies examining both sensations in combination are lacking. In the present study, dyspnea was induced in 7 healthy volunteers by breathing through inspiratory resistive loads and the effects were compared with those of a heat pain stimulus. End-tidal partial pressures of carbon dioxide $\left(\mathrm{PET}_{\mathrm{CO}_{2}}\right)$, inspiratory time $(\mathrm{Ti})$, breathing frequency $(f)$, experienced unpleasantness, and intensity were measured. No difference was observed between dyspnea and pain in experienced intensity and unpleasantness $(p>.05)$. During dyspneic stimulation, slightly higher $T i$ was found than for pain $(p<.08)$. $\mathrm{PET}_{\mathrm{CO}_{2}}$ showed slight increases during the dyspneic versus the baseline and painful conditions $\left(\Delta \mathrm{PET}_{\mathrm{CO}_{2}}=1.5\right.$ and $1.3 \mathrm{mmHg}$, respectively; $p<.01$ and $\left.p<.05\right)$. This study shows that the effects of dyspnea and heat pain can be compared within one experiment; both stimuli can be presented with similar intensity and unpleasantness, which is a prerequisite for comparing responses to them. The changes in $\mathrm{PET}_{\mathrm{CO}_{2}}$ between our conditions were minimal, allowing an application of the present design to future fMRI studies.
\end{abstract}

Dyspnea, or breathlessness, is the subjective experience of breathing discomfort that comprises qualitatively distinct sensations that can vary in intensity. This sensory experience evolves from interactions among multiple physiological, psychological, social, and environmental factors (American Thoracic Society, 1999). Dyspnea is an aversive and frightening symptom in various cardiopulmonary and other diseases (American Thoracic Society, 1999; Rao \& Gray, 2003) and a cardinal symptom in asthma and chronic obstructive pulmonary disease, causing reductions in functional status and quality of life, as well as an enormous socioeconomic burden (NHLBI/WHO, 2001, 2002). However, adequate perception of the onset and severity of breathlessness is a major component of disease selfmanagement programs, particularly for asthma (Dahme, Schandry, \& Leopold, 2000; NHLBI/WHO, 2002). Failure to perceive the severity of a developing bronchoconstriction can lead to delays in seeking help, inadequate utilization of effective medications, and at worst, may result in avoidable deaths (Barnes, 1994; Magadle, Berar-Yanay, \& Weiner, 2002; Rodrigo, Rodrigo, \& Hall, 2004).

Recent research has examined several peripheral input mechanisms contributing to the perception of dyspnea (American Thoracic Society, 1999; Davenport \& Reep, 1994; Shea, Banzett, \& Lansing, 1994), but our knowledge of the cortical structures involved in the perception of dyspnea is still limited (Banzett, Mulnier, et al., 2000; Guz, 1997; Manning \& Schwartzstein, 1995; von Leupoldt \& Dahme, 2005a). First neuroimaging studies on dyspnea showed activation of distinct brain areas (e.g., anterior insular, anterior cingulate cortex), which are similar to those found activated in the majority of studies on the perception of various pain stimuli (Banzett, Mulnier, et al., 2000; Evans et al., 2002; Liotti et al., 2001; Peiffer, Poline, Thivard, Aubier, \& Samson, 2001; for a review, see von Leupoldt \& Dahme, 2005a).

As previously explicated by Banzett and Moosavi (2001), both are subjectively perceived physiological sensations and both share the unpleasant nature. The perception of dyspnea and pain warns the conscious brain of disturbances in the physiological state and strongly motivates adaptive behavior to modify this aversive situation. Thus, behavioral plans and motor actions can be initiated following the perceptual process. Furthermore, many patients with different diseases suffer from both aversive symptoms (Gehlbach \& Geppert, 2004; Rao \& Gray, 2003). Despite many similarities between dyspnea and pain and the high comorbidity of both sensations, our knowledge about interactions regarding their perception is markedly reduced. Only one study on this issue is available, reporting increased dyspnea ratings when a tourniquet pain was added, whereas tourniquet pain showed a nonsignificant trend to decrease after additional induction of dyspnea (Nishino, Shimoyama, Ide, \& Isono, 1999). Because of the various similarities between dyspnea and pain, it was recently suggested to adopt successful methods and strategies from pain research, which is by far more advanced, for investigations into dyspnea (Banzett, Dempsey, O’Donnell, \& Wamboldt, 2000; Banzett \& Moosavi, 2001). For example, the realization of the multidimensionality of pain, e.g., the difference between sensory and affective aspects of this sensation, has been a key contribution that has led to the development of highly useful pain measurement instruments. Although first attempts seem to suggest a similar multidimensionality of perceived breathlessness (Carrieri-Kohlman, Gormley,

A. von Leupoldt, andreas.vonleupoldt@uni-hamburg.de 
Douglas, Paul, \& Stulbarg, 1996; Lehrer, Hochron, Isenberg, Rausch, \& Carr, 1993; von Leupoldt \& Dahme, 2005b; Wilson \& Jones, 1991), this issue has still received little attention (Banzett \& Moosavi, 2001; von Leupoldt $\&$ Dahme, 2005a). To increase the understanding about a common perceptual processing of dyspnea and pain, it was suggested to compare both sensations within one study (Banzett \& Moosavi, 2001; von Leupoldt \& Dahme, 2005a). However, when examining responses to different sensations it is necessary to use experimental stimuli of comparable magnitude and quality. Moreover, a comparison of cortical responses during the perception of different sensations with functional magnetic resonance imaging (fMRI) requires comparable levels of arterial carbon dioxide tension $\left(\mathrm{Pa}_{\mathrm{CO}_{2}}\right)$. Since fMRI measures regional cerebral blood flow (rCBF) to characterize activity in distinct brain areas, which is increased locally during neural activity (Binder \& Rao, 1994), it is necessary to prevent artifacts of strong changes in global cerebral blood flow (gCBF). These changes in gCBF can occur due to changes in $\mathrm{Pa}_{\mathrm{CO}_{2}}$ (Cohen, Ugurbil, \& Kim, 2002; Posse, Kemna, Elghahwagi, Wiese, \& Kiselev, 2001; Ramsey et al., 1993).

We examined whether dyspnea and pain can be compared within a single study. Therefore, comparable stimulus sizes of inspiratory resistive loads and heat pain stimuli were created individually and presented to healthy volunteers. Responses in end-tidal partial pressures of carbon dioxide $\left(\mathrm{PET}_{\mathrm{CO}_{2}}\right)$ and respiration, as well as the perceived intensity, unpleasantness, and quality of both sensations, were compared for the two types of stimuli, thus providing initial data for future studies with an fMRI methodology.

\section{METHOD}

\section{Participants}

Seven healthy and nonsmoking Caucasian volunteers of age 21 or over were studied. The mean age was $31.0 \pm 4.2$ years (mean $\pm S D$ ). All participants were naive to the study hypotheses. Pregnancy, acute complaints of the respiratory tract, or chronic medical conditions such as asthma, chronic pain, or sensory deficits were exclusion criteria. After giving written informed consent, volunteers underwent a screening spirometry (Quanjer et al., 1993). Participants were free to withdraw at any time during the experiment. The study protocol was approved by the ethics committee of the local medical association.

\section{Measurement of Lung Function}

Spirometry was performed using a Spiroset 3000 (Hörmann Medizintechnik GmbH, Germany) according to standards published by the European Respiratory Society (Quanjer et al., 1993). Spirometry was performed with the participants standing and using nose clips.

\section{Inspiratory Resistive Loads}

During tests, volunteers breathed via a mouthpiece through a breathing circuit that consisted of a two-way valve (Jaeger-Toennies $\mathrm{GmbH}$, Germany) while wearing a nose clip. At the end of the inspiratory port, resistive loads, ranging from 0.99 to $3.30 \mathrm{kPa} / 1 / \mathrm{sec}$, could be applied and removed quickly. During the baseline and heat pain conditions, no load was presented. Respiratory loads, which increase inspiratory time and decrease breathing frequency, are commonly used to induce dyspnea by increasing the work and effort of breathing (Harver \& Mahler, 1998). The expiratory port was unloaded in order to prevent any interference with the $\mathrm{PET}_{\mathrm{CO}_{2}}$ measurement as a result of possible rebreathing of $\mathrm{CO}_{2}$.

\section{Heat Pain}

In order to apply a pain stimulus of a tonic quality comparable to that of the induced dyspnea, a heat stimulus was chosen, which is a method commonly employed in pain studies (Granot, Sprecher, \& Yarnitsky, 2003). This stimulus was produced by a Thermal NeuroSensory Analyzer-II system (TSA-II; Medoc Advanced Medical Systems, Israel) with a $30 \times 30 \mathrm{~mm}^{2}$ Peltier contact thermode placed below the sternum on the skin surface. The TSA-II generates different temperatures within seconds and prevents intraindividual overstimulation with an implemented security system. Therefore, individual tonic heat pain limits were determined prior to tests. Adaptation temperature during baselines and loaded breathing was $32^{\circ} \mathrm{C}$, which was automatically increased to the individual painful heat within the first $20 \mathrm{sec}$ of the heat pain conditions. This ramping procedure was chosen to mirror the gradual increase of dyspnea. Pilot tests had shown that inspiratory resistive loading required about $20 \mathrm{sec}$ to induce a targeted level of increased work and effort of breathing.

\section{Measurement of $\mathrm{PET}_{\mathrm{CO}_{2}}$ and Ventilation}

$\mathrm{PET}_{\mathrm{CO}_{2}}$, which approximates $\mathrm{Pa}_{\mathrm{CO}_{2}}$ (Gardner, 1994), was measured continuously at the expiratory port of the two-way valve using a ZAN fast response $\mathrm{CO}_{2}$ transducer (Korn Medizintechnik, Germany). The output signal was conveyed to an MP30 biosignal recording unit (BIOPAC Systems, Inc., Santa Barbara, CA), which also measured inspiratory time $(\mathrm{Ti})$ and breathing frequency $(f)$. The MP30 was connected to an iBook notebook computer (Apple Computer, Cupertino, CA) running the biosignal software package Biopac Student Lab Pro. All data were stored on the notebook and analyzed offline breath by breath.

\section{Measurement of Perceived Sensations}

During pretests, participants repeatedly rated the intensity of different resistive loads and heat pain stimuli, presented for 1 min each on a modified Borg scale (Borg, 1998) from 0 to $10(0=$ not noticeable, $10=$ maximum that can be tolerated $)$. Dyspnea was defined as a sensation of uncomfortable restricted breathing.

During the main test, volunteers rated the perceived sensations on two dimensions, in light of the current awareness of the multidimensionality of pain, and presumably of dyspnea. After each condition, the experienced degrees of unpleasantness ( $=$ affective) and intensity (= sensory) were rated on separate visual-analogue scales (VASs; Noseda, Schmerber, Prigogine, \& Yernault, 1992) ranging from 0 to $10 \mathrm{~cm}(0=$ not noticeable/unpleasant, $10=$ maximally imaginable intensity/unpleasantness). VASs were used for the main tests in order to prevent carryover effects from the pretests, such as the potential for participants to use the same numerical value for all conditions. VASs for unpleasantness and intensity were presented in randomized order on a monitor in front of the volunteers. Both dimensions were explained in detail, and the experimenter made sure that the phrases were adequately understood. The following standardized instruction for intensity was given to the participants.

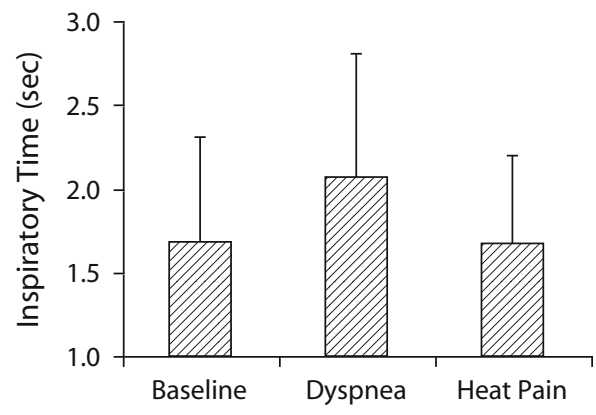

Figure 1. Inspiratory time during the baseline, dyspneic, and heat pain conditions. Data represent the group means + standard deviations. 
Table 1

Baseline Characteristics of Participants

\begin{tabular}{ll}
\hline \multicolumn{1}{c}{ Measure } & \multicolumn{1}{c}{ Baseline } \\
\hline Age, years & $31.0 \pm 4.2$ \\
Subjects (male, female) & $7(3,4)$ \\
Weight, $\mathrm{kg}$ & $71.6 \pm 16.2$ \\
Height, cm & $171.7 \pm 8.7$ \\
Forced expiratory volume in 1st sec, liters & $3.99 \pm 0.75$ \\
Forced expiratory volume in 1st sec, \% predicted & $108.57 \pm 9.27$ \\
\hline Note &
\end{tabular}

Note-Data are presented as means $\pm S D$ s.

The intensity means the pure level or magnitude of the sensation. It is like a physical measure, e.g., $\mathrm{kg}$ or $\mathrm{cm}$. Intensity contains no affective evaluation in terms of pleasant or unpleasant, whether I like it, or it is terrible. A low intensity standswithout affective connotation - simply for a low magnitude of the perceived stimulus. A high intensity stands for a high magnitude of the stimulus but without expressing whether this feels rather pleasant or unpleasant.

The standardized instruction for unpleasantness was as follows.

The unpleasantness expresses the affective evaluation of the sensation regardless of the stimulus intensity being low or high. Unpleasantness describes how much you affectively dislike something or feel terrible about it. A low unpleasantness means that the stimulus does not feel bad. A high unpleasantness means that the stimulus feels very unpleasant or terrible regardless whether the magnitude of the stimulus is low or high.

After the main test, participants rated the perceived qualities of each of the two sensations on an exploratory verbal descriptor scale from 1 to $4(1=$ not true, $4=$ absolutely true $)$. The scale, which displays 14 affective adjectives (see Figure 5 below), was derived from a modified paper-and-pencil version of the SES (Geissner, 1996), a validated German multidimensional pain questionnaire.

\section{Procedure}

After the contact thermode was positioned and adjusted, standardized instructions were given. Each volunteer was seated in a recliner, and the light was dimmed. Participants breathed through the breathing circuit with the nose occluded. During pretests, inspiratory resistive loads and heat stimuli of increasing magnitudes were presented, separately for each sensation, in two successive runs. Load and heat stimuli were presented for 1-min epochs separated by 1-min "rest" epochs, in which unloaded breathing and a nonpainful temperature of $32^{\circ} \mathrm{C}$, respectively, were presented. After each epoch, volunteers rated the perceived intensity of dyspnea or pain on a Borg scale. The individual inspiratory load and heat stimulus that induced a corresponding Borg value of about 5 (= strong intensity) were chosen for the main test.

During the main test, eight trials of a nonpainful, unloaded baseline condition, four of loaded breathing, and four of heat pain were presented for $1 \mathrm{~min}$ each. After each baseline trial, either a load or a heat stimulus was presented in randomized order. Immediately after each trial, volunteers rated the perceived degree of unpleasantness and intensity on separate VASs. Immediately after each 16-min run, the experienced qualities of both the dyspnea and heat pain were rated on the modified SES verbal descriptor scales. The volunteers were then given further background information and released.

\section{Data Analysis}

$\mathrm{PET}_{\mathrm{CO}_{2}}, T i, f$, and VAS scores were averaged for the baseline, dyspneic, and painful conditions. Means \pm standard deviations $(S D s)$ are reported. The means were separately analyzed as a dependent variable in one- and two-way repeated measures ANOVAs, as indicated. Bonferroni-corrected, univariate, pairwise comparisons were then calculated for further exploration of the main effects. All analy- ses were conducted with SPSS 11.5 software (SPSS, Inc., Chicago, IL). A Greenhouse-Geisser correction of degrees of freedom and a $5 \%$ significance level were applied. Furthermore, post hoc power tests for matched-pairs $t$ tests were performed for each comparison in order to indicate the sample sizes $\left(n_{\text {est }}\right)$ required to attain significance in future studies on this topic. The $n_{\text {est }}$ estimates are based on an assumed test power of $(1-\beta)=.95$, with $\alpha=.05$. All power analyses were calculated with $\mathrm{G} *$ Power (Erdfelder, Faul, \& Buchner, 1996), a free statistical software package (available at www.psycho .uni-duesseldorf.de/aap/projects/gpower).

\section{RESULTS}

All participants tolerated the exposures well and completed the whole protocol. The means of the presented inspiratory resistive loads and heat pain stimuli were $2.45 \pm$ $0.72 \mathrm{kPa} / \mathrm{l} / \mathrm{sec}$ and $46.0 \pm 0.61^{\circ} \mathrm{C}$, respectively. Table 1 shows the baseline characteristics of the volunteers.

\section{Ventilation and $\mathrm{PET}_{\mathrm{CO}_{2}}$}

Inspiratory time $T i$ (Figure 1) increased from $1.69 \pm$ $0.64 \mathrm{sec}$ during baseline trials to $2.07 \pm 0.75 \mathrm{sec}$ during loaded breathing $\left(p=.020\right.$, power $\left.=.92, n_{\text {est }}=8\right)$. The difference between $T i$ during heat pain $(1.67 \pm 0.55 \mathrm{sec})$ and during loaded breathing was marginally significant $\left(p=.075\right.$, power $\left.=.70, n_{\mathrm{est}}=12\right)$. There was no significant difference in $T i$ between the baseline and heat pain conditions (power $=.06, n_{\mathrm{est}}=1,085$ ).

Breathing frequency $f$ (Figure 2) decreased from $15.07 \pm 3.33$ breaths/min during baseline to $13.26 \pm 3.10$ breaths $/$ min during loaded breathing $(p=.009$, power $=$ $\left..98, n_{\text {est }}=6\right)$. The difference between $f$ during heat pain $(14.69 \pm 2.66 \mathrm{breaths} / \mathrm{min})$ and during loaded breathing was not significant (power $=.40, n_{\mathrm{est}}=24$ ), and there was also no significant difference in $f$ between the baseline and heat pain conditions ( power $=.10, n_{\text {est }}=155$ ).

$\mathrm{PET}_{\mathrm{CO}_{2}}$ (Figure 3) increased from $38.25 \pm 5.17 \mathrm{mmHg}$ during baseline to $39.75 \pm 5.23 \mathrm{mmHg}$ during loaded breathing ( $p=.006$, power $\left.=.99, n_{\mathrm{est}}=6\right)$. During heat pain $(38.46 \pm 5.27 \mathrm{mmHg}), \mathrm{PET}_{\mathrm{CO}_{2}}$ did not change significantly from baseline ( power $=.21, n_{\text {est }}=50$ ), but the heat pain value was significantly lower than during loaded breathing $\left(p=.027\right.$, power $\left.=.88, n_{\mathrm{est}}=9\right)$.

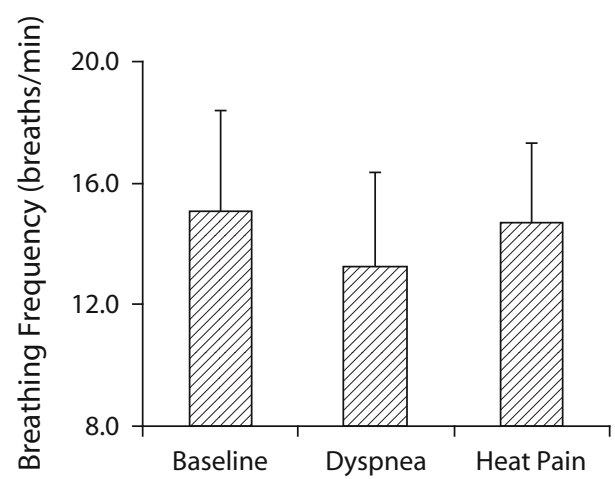

Figure 2. Breathing frequency during the baseline, dyspneic, and heat pain conditions. Data represent the group means + standard deviations. 


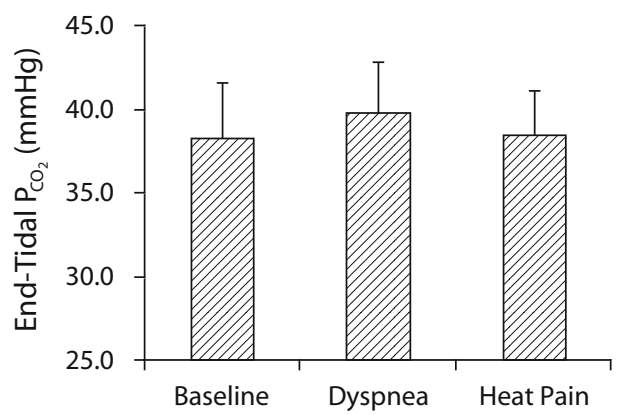

Figure 3. End-tidal $\mathrm{CO}_{2}$ partial pressure levels $\left(\mathrm{P}_{\mathrm{CO}_{2}}\right)$ during the baseline, dyspneic, and heat pain conditions. Data represent the group means + standard deviations.

\section{Perceived Sensations}

VAS ratings (Figure 4) for experienced intensity showed a significant increase from baseline $(0.5 \pm 0.5 \mathrm{~cm})$ for loaded breathing $(4.9 \pm 1.4 \mathrm{~cm} ; p=.001$, power $=$ $\left.1.00, n_{\text {est }}=4\right)$ and for heat pain $(5.3 \pm 2.3 \mathrm{~cm} ; p=.002$, power $=1.00, n_{\text {est }}=5$ ). The VAS ratings for experienced unpleasantness also increased from baseline $(0.5 \pm$ $0.5 \mathrm{~cm})$ for both loaded breathing $(5.0 \pm 3.0 \mathrm{~cm} ; p=$ .017 , power $\left.=.94, n_{\mathrm{est}}=7\right)$ and heat pain $(5.1 \pm 2.9 \mathrm{~cm}$; $p=.013$, power $=.96, n_{\mathrm{est}}=7$ ). No significant differences between dyspneic and painful stimulation were obtained in either experienced intensity (power $=.09, n_{\text {est }}=$ 210 ) or unpleasantness (power $=.05, n_{\text {est }}=8,125$ ).

The data on the verbal descriptor scale were examined in an exploratory manner, since no specific hypotheses could be derived from the previous studies. Among the four most prominent verbal descriptors chosen to characterize the qualitative nature of each sensation, three were generated for both loaded breathing and heat pain (see Figure 5). These descriptors were heavy, enervating, and agonizing. However, no further statistical tests were conducted to follow up these exploratory and descriptive findings.

\section{DISCUSSION}

Dyspnea and pain are physical sensations that have many characteristics in common. Both are highly aversive and alarming sensations that strongly motivate adaptive behavior, and thus both are important for maintaining homeostasis. Furthermore, the perception of both sensations might be processed by a common cortical network. Although a large body of experimental studies exists in which dyspnea and pain have been examined separately, only one study has focused on interactions of both sensations (Nishino et al., 1999). Therefore, some researchers have suggested comparing dyspnea and pain within one experimental context in order to allow more precise conclusions about the perceptual similarities between the sensations (Banzett \& Moosavi, 2001; von Leupoldt \& Dahme, 2005a).

Our results are the first to show that dyspnea and pain can be compared within one experimental design by using inspiratory resistive loads and painful heat. Both sensa- tions could be presented with comparable magnitudes of perceived intensity and unpleasantness, which was confirmed by the respective VAS ratings that showed no differences between the dyspneic and heat pain conditions. Such comparability is an important prerequisite when responses to different sensations are examined. To obtain these corresponding stimulus magnitudes, extensive pretests were performed.

The data in the present study demonstrate that comparable tonic stimuli induced different ventilatory responses. As expected, the dyspneic condition induced a significant increase in $T i$ and a decrease in $f$ in comparison with the baseline condition. This is in line with well-known effects of resistive loads (Harver \& Mahler, 1998), thus confirming the effectiveness of inducing dyspnea in the present study. Ti during dyspneic stimulation showed a marginally significant increase when compared with $T i$ during painful stimulation. No differences in $T i$ and $f$ were obtained between the heat pain and baseline conditions. This seems to contradict previous findings, which have reported increased ventilation during pain that was induced with different techniques (Dockery \& Drummond, 2002; Sarton et al., 1997). These pain-induced ventilatory increases were, however, primarily caused by augmented inspiratory flow rates and not by significant changes in $T i$ and $f$ (Dockery \& Drummond, 2002; Sarton et al., 1997). Thus, our results for $T i$ and $f$ during painful heat converge with the previous reports.

The results for $\mathrm{PET}_{\mathrm{CO}_{2}}$ showed increases during the dyspneic condition in comparison with both the baseline and heat pain conditions, and no difference was obtained between baseline and heat pain. Although significant, the increases in $\mathrm{PET}_{\mathrm{CO}_{2}}\left(\Delta \mathrm{PET}_{\mathrm{CO}_{2}}=1.5\right.$ and $\left.1.3 \mathrm{mmHg}\right)$ were not pronounced and were within the range of spontaneous fluctuations, which also confirms previous findings (Yanos, Banner, Stanko, Gentry, \& Greenawalt, 1990). This is important with regard to an application of the present design within fMRI settings. fMRI characterizes brain activity by measuring differences in $\mathrm{rCBF}$. Changes

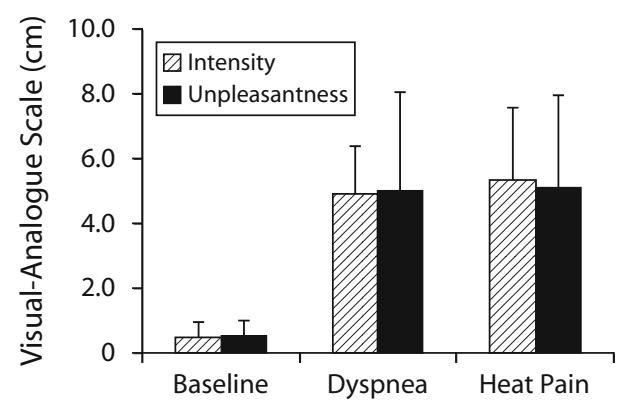

Figure 4. Visual-analogue scale ratings for perceived intensity and unpleasantness during the baseline, dyspneic, and heat pain conditions. No differences in intensity or unpleasantness were obtained between the dyspneic and heat pain conditions, but differences were found for both between the dyspneic and baseline conditions ( $p s=.001$ and .017 for intensity and unpleasantness, respectively) and between the heat pain and baseline conditions ( $p s=.002$ and .013 , respectively). Data represent the group means + standard deviations. 
in $\mathrm{Pa}_{\mathrm{CO}_{2}}$ can change the gCBF, and thus can be highly confounding for measuring local activity with fMRI (Ramsey et al., 1993). However, with regard to recent findings (Cohen et al., 2002; Posse et al., 2001), obtained increases in $\mathrm{PET}_{\mathrm{CO}_{2}}$ of up to $1.5 \mathrm{mmHg}$ should still allow a clear differentiation between stimulus-induced changes in the fMRI signal and those related to increases in $\mathrm{gCBF}$ as a result of increased $\mathrm{Pa}_{\mathrm{CO}_{2}}$. According to Cohen et al.'s linear regression equation, an increase in $\mathrm{PET}_{\mathrm{CO}_{2}}$ of $1.5 \mathrm{mmHg}$ results in a change of the normalized baseline MRI signal of only 0.006 . This would influence the peak height of the BOLD signal by less than one percent, which is negligible.

Our exploratory results concerning the quality of both sensations have revealed that both dyspnea and pain are at least to some degree perceived in comparable manners. Among the four main verbal descriptors chosen to characterize the stimuli from our list of affective adjectives, three of the descriptors were chosen for both sensations: heavy, enervating, and agonizing. This result provides further evidence for similarities in perceptual processing between dyspnea and pain, such as those discussed by
Banzett and Moosavi (2001). However, other, less prominent descriptors seemed to differentiate more between the two sensations, and future studies are clearly needed to extend our exploratory results on affective similarities. It remains to be established whether cognitive interventions that influence either attentional state or affective context, which have been shown to reduce the perception of pain (Villemure \& Bushnell, 2002), can also be adopted for reducing the perception of dyspnea. In this regard, it might be interesting to examine which dimension of perceived dyspnea (intensity or unpleasantness) is more susceptible to these interventions and whether this sensitivity is mirrored by different cortical activations, as has been shown in pain studies.

However, aside from the initial data it has provided for advancing the understanding of the relationship between dyspnea and pain, the present study has limitations that should be mentioned. With regard to our post hoc power analyses, sample size might have limited our study's ability to obtain significant differences in some comparisons. Future studies might therefore benefit from the sample size estimates we have provided in the planning of an experi-

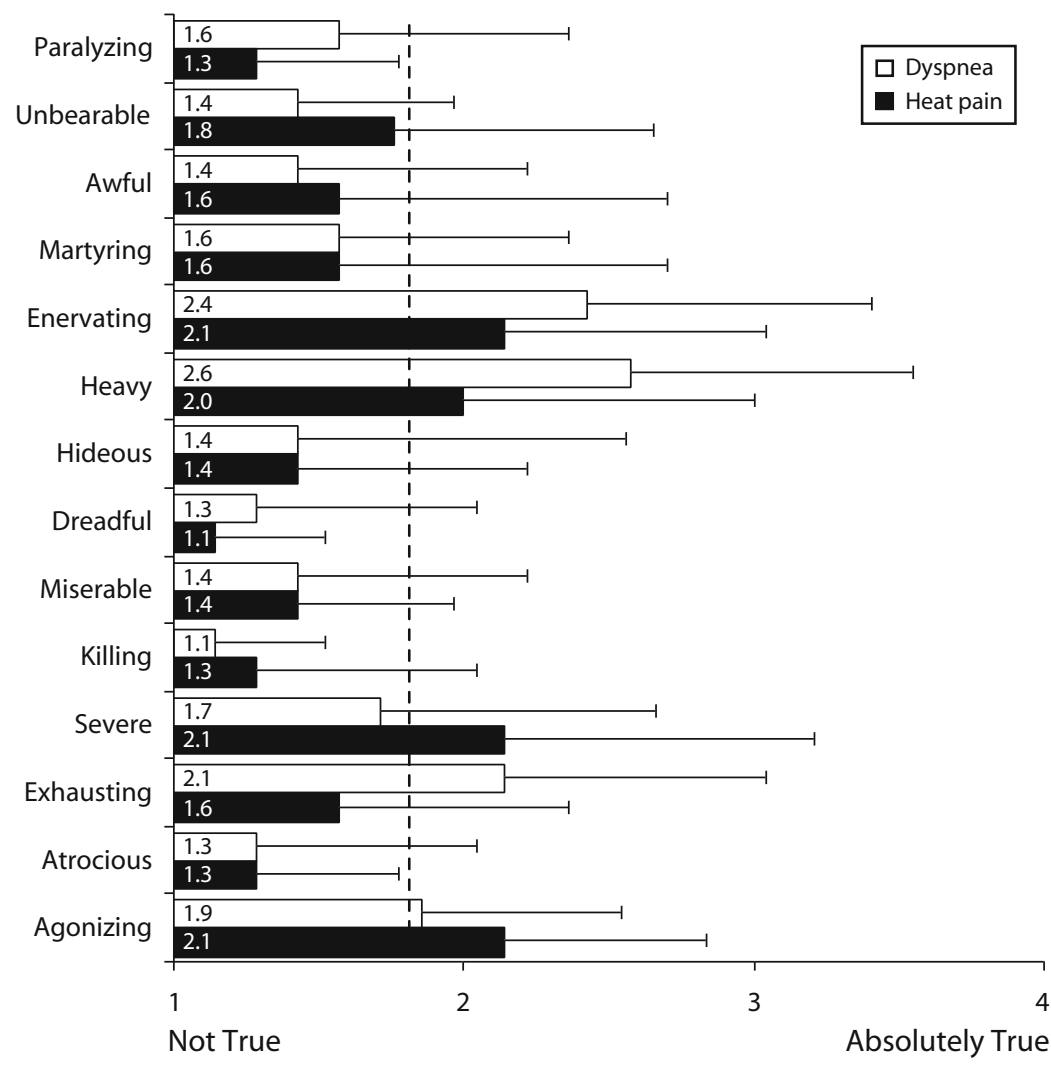

Figure 5. Ratings for the perceived qualities of dyspnea and heat pain on a paperand-pencil verbal descriptor scale from 1 to 4 . Our exploratory scale contains 14 affective adjectives derived from the validated German SES multidimensional pain questionnaire (Geissner, 1996). For both dyspnea and heat pain, the descriptors heavy, enervating, and agonizing were among the four most prominent adjectives (those extending to the right of the dotted line) chosen to characterize the sensations. The data represent group means + standard deviations. The displayed adjectives are English translations of those in the German scale, but note that only the German forms were rated by the participants. 
mental design. Furthermore, in this study we examined responses to different stimuli of comparable magnitude. For a more detailed and extended examination of the similarities between dyspnea and pain, future studies should also employ an experimental approach that includes multiple levels of both stimuli. This might yield further information on how the sensations are perceived with respect to one another, as well as on how the dimensions of intensity and unpleasantness relate to one another. On the basis of our results, one could argue that these two perceptual dimensions cannot be differentiated by participants. Previous results, however, have shown the opposite finding for both dyspnea and pain, although a few findings corroborating ours have also been reported in the field of pain research (see, e.g., Chapman et al., 2001). The previous studies that have clearly demonstrated a difference between intensity and unpleasantness in the perception of dyspnea have used increasing levels of dyspnea (Carrieri-Kohlman et al., 1996; von Leupoldt \& Dahme, 2005b; Wilson \& Jones, 1991). Perhaps, then, a differentiation between these dimensions is facilitated by comparing different levels of the sensation. However, future studies with approaches that include both single and multiple stimulus levels will be necessary in order to further explore this question.

\section{CONCLUSION}

In conclusion, our initial data demonstrate that dyspnea and heat pain can be compared within one study in which stimuli of similar magnitudes are presented. Changes in $\mathrm{PET}_{\mathrm{CO}_{2}}$ are minimal in response to both dyspneic and painful sensations, which should allow an adaptation of the present design for future fMRI studies.

\section{AUTHOR NOTE}

The authors thank Isgard Kavukcuoğlu, Cetin Kova, and Elke Jedamzik for assistance with laboratory procedures; Caryn Edmondson and Thomas Ritz for proofreading and commenting on the manuscript; and the students who volunteered in the study. The authors declare that they have no financial interests in either the products referred to in this article or their competitors. Correspondence relating to this article may be sent to A. von Leupoldt, Psychological Institute III, University of Hamburg, Von-Melle-Park 5, 20146 Hamburg, Germany (e-mail: andreas .vonleupoldt@uni-hamburg.de).

\section{REFERENCES}

American Thoracic Society (1999). Dyspnea: Mechanisms, assessment, and management. A consensus statement. American Journal of Respiratory \& Critical Care Medicine, 159, 321-340.

Banzett, R. B., Dempsey, J. A., O'Donnell, D. E., \& Wamboldt, M. Z. (2000). Symptom perception and respiratory sensation in asthma. American Journal of Respiratory \& Critical Care Medicine, 162, 1178-1182.

Banzett, R. B., \& Moosavi, S. H. (2001). Dyspnea and pain: Similarities and contrasts between two very unpleasant sensations. APS Bulletin, 11, 1-8.

Banzett, R. B., Mulnier, H. E., Murphy, K., Rosen, S. D., Wise, R. J., \& ADAMs, L. (2000). Breathlessness in humans activates insular cortex. NeuroReport, 11, 2117-2120.

BARNES, P. J. (1994). Blunted perception and death from asthma. New England Journal of Medicine, 330, 1383-1384.

BINDER, J. R., \& RAO, S. M. (1994). Human brain mapping with functional magnetic resonance imaging. In A. Kertesz (Ed.), Localization and neuroimaging in neuropsychology (pp. 185-212). San Diego: Academic Press.
BorG, G. (1998). Borg's perceived exertion and pain scales. Champaign, IL: Human Kinetics.

Carrieri-Kohlman, V., Gormley, J. M., Douglas, M. K., Paul, S. M., \& Stulbarg, M. S. (1996). Differentiation between dyspnea and its affective components. Western Journal of Nursing Research, 18, 626-642.

Chapman, C. R., Nakamura, Y., Donaldson, G. W., Jacobson, R. C., Bradshaw, D. H., Flores, L., \& Chapman, C. N. (2001). Sensory and affective dimensions of phasic pain are indistinguishable in the self-report and psychophysiology of normal laboratory subjects. Journal of Pain, 2, 279-294.

Cohen, E. R., Ugurbil, K., \& Kim, S. G. (2002). Effect of basal conditions on the magnitude and dynamics of the blood oxygenation level-dependent fMRI response. Journal of Cerebral Blood Flow \& Metabolism, 22, 1042-1053.

Dahme, B., Schandry, R., \& Leopold, C. (2000). Symptomwahrnehmung beim Asthma bronchiale [Symptom perception in bronchial asthma]. In F. Petermann \& P. Warschburger (Eds.), Asthma bronchiale (pp. 99-114). Göttingen: Hogrefe.

Davenport, P. W., \& Reep, R. L. (1994). Cerebral cortex and respiration. In J. A. Dempsey \& A. I. Pack (Eds.), Regulation of breathing (2nd ed., pp. 365-388). New York: Dekker.

Dockery, M. P., \& Drummond, G. B. (2002). Respiratory response to skin incision during anaesthesia with infusions of propofol and alfentanil. British Journal of Anaesthesiology, 88, 649-652.

ERDFELDER, E., FAUL, F., \& BuCHNER, A. (1996). GPOWER: A general power analysis program. Behavior Research Methods, Instruments, \& Computers, 28, 1-11.

Evans, K. C., Banzett, R. B., Adams, L., McKay, L., Frackowiak, R. S., \& Corfield, D. R. (2002). BOLD fMRI identifies limbic, paralimbic, and cerebellar activation during air hunger. Journal of Neurophysiology, 88, 1500-1511.

Gardner, W. (1994). Measurement of end-tidal $\mathrm{P}_{\mathrm{CO}_{2}}$ and $\mathrm{P}_{\mathrm{O}_{2}}$. Biofeedback \& Self-Regulation, 19, 103-113.

Gehlbach, B. K., \& GepPert, E. (2004). The pulmonary manifestations of left heart failure. Chest, 125, 669-682.

GEISSNER, E. (1996). Die Schmerzempfindungsskala SES [The SES pain perception scale]. Göttingen: Hogrefe.

Granot, M., Sprecher, E., \& Yarnitsky, D. (2003). Psychophysics of phasic and tonic heat pain stimuli by quantitative sensory testing in healthy subjects. European Journal of Pain, 7, 139-143.

Guz, A. (1997). Brain, breathing and breathlessness. Respiratory Physiology, 109, 197-204.

Harver, A., \& Mahler, D. A. (1998). Perception of increased resistance to breathing. In H. Kotses \& A. Harver (Eds.), Self-management of asthma (pp. 35-61). New York: Dekker.

Lehrer, P. M., Hochron, S. M., Isenberg, S., Rausch, L., \& Carr, R. (1993). The Asthma Symptom Profile: A psychophysically based scale for assessment of asthma symptoms. Journal of Psychosomatic Research, 37, 515-521.

Liotti, M., Brannan, S., Egan, G., Shade, R., Madden, L., AbPlanALP, B., ET AL. (2001). Brain responses associated with consciousness of breathlessness (air hunger). Proceedings of the National Academy of Sciences, 98, 2035-2040.

Magadle, R., Berar-Yanay, N., \& Weiner, P. (2002). The risk of hospitalization and near-fatal and fatal asthma in relation to the perception of dyspnea. Chest, 121, 329-333.

Manning, H. L., \& Schwartzstein, R. M. (1995). Pathophysiology of dyspnea. New England Journal of Medicine, 333, 1547-1553.

NHLBI/WHO (2001). Workshop report: Global strategy for the diagnosis, management, and prevention of chronic obstructive pulmonary disease (Pub. No. 2701). Bethesda, MD: National Institutes of Health.

NHLBI/WHO (2002). Workshop report: Global strategy for asthma management and prevention (Pub. No. 02-3659, 2002 rev. ed.). Bethesda, MD: National Institutes of Health.

Nishino, T., Shimoyama, N., IDE, T., \& Isono, S. (1999). Experimental pain augments experimental dyspnea, but not vice versa in human volunteers. Anesthesiology, 91, 1633-1638.

Noseda, A., Schmerber, J., Prigogine, T., \& Yernault, J. C. (1992). Perceived effect on shortness of breath of an acute inhalation of saline or terbutaline: Variability and sensitivity of a visual analogue scale in patients with asthma or COPD. European Respiratory Journal, 5, 1043-1053. 
Peiffer, C., Poline, J. B., Thivard, L., Aubier, M., \& Samson, Y (2001). Neural substrates for the perception of acutely induced dyspnea. American Journal of Respiratory \& Critical Care Medicine, 163, 951-957.

Posse, S., Kemna, L. J., Elghahwagi, B., Wiese, S., \& Kiselev, V. G. (2001). Effect of graded hypo- and hypercapnia on fMRI contrast in visual cortex: Quantification of $\mathrm{T}(*)(2)$ changes by multiecho EPI. Magnetic Resonance in Medicine, 46, 264-271.

Quanjer, P. H., Tammeling, G. J., Cotes, J. E., Pedersen, O. F., PesLIN, R., \& YeRnAUlt, J. C. (1993). Lung volumes and forced ventilatory flows. European Respiratory Journal, 6(Suppl. 16), 5-40.

Ramsey, S. C., Murphy, K., Shea, S. A., Friston, K. J., Lammertsma, A. A., Clark, J. C., ET AL. (1993). Changes in global cerebral blood flow in humans: Effect on regional cerebral blood flow during a neural activation task. Journal of Physiology, 471, 521-534.

RaO, A. B., \& GRAY, D. (2003). Breathlessness in hospitalised adult patients. Postgraduate Medical Journal, 79, 681-685.

Rodrigo, G. J., Rodrigo, C., \& Hall, J. B. (2004). Acute asthma in adults: A review. Chest, 125, 1081-1102.

Sarton, E., Dahan, A., Teppema, L., Berkenbosch, A., van den ELSEN, M., \& VAN KLEEF, J. (1997). Influence of acute pain induced by activation of cutaneous nociceptors on ventilatory control. Anesthesiology, 87, 289-296.
Shea, S. A., Banzett, R. B., \& Lansing, R. W. (1994). Respiratory sensations and their role in the control of breathing. In J. A. Dempsey \& A. I. Pack (Eds.), Regulation of breathing (2nd ed., pp. 923-957). New York: Dekker.

Villemure, C., \& Bushnell, M. C. (2002). Cognitive modulation of pain: How do attention and emotion influence pain processing? Pain, 95, 195-199.

von Leupoldt, A., \& Dahme, B. (2005a). Cortical substrates for the perception of dyspnea. Chest, 128, 345-354.

Von Leupoldt, A., \& DAhme, B. (2005b). Differentiation between the sensory and affective dimension of dyspnea during resistive load breathing in normal subjects. Chest, 128, 3345-3349.

Wilson, R. C., \& Jones, P. W. (1991). Differentiation between the intensity of breathlessness and the distress it evokes in normal subjects during exercise. Clinical Science, 80, 65-70.

Yanos, J., Banner, A., Stanko, R., Gentry, S., \& Greenawalt, K. (1990). Ventilatory responses to inspiratory threshold loading in humans. Journal of Applied Physiology, 68, 2511-2520.

(Manuscript received September 11, 2005; revision accepted for publication November 11, 2005.) 